\title{
A Valuation Model for the Variable Rate Demand Obligation
}

\author{
Vince Hooper ${ }^{1}$, John Pointon ${ }^{2}$ \\ ${ }^{1}$ School of Economics and Management, Xiamen University Malaysia, Kuala Lumpur, Malaysia \\ ${ }^{2}$ University of Plymouth, Plymouth, UK \\ Email: hoovcomm@hotmail.com
}

How to cite this paper: Hooper, V. and Pointon, J. (2019) A Valuation Model for the Variable Rate Demand Obligation. Journal of Mathematical Finance, 9, 388-393.

https://doi.org/10.4236/jmf.2019.93022

Received: February 1, 2019

Accepted: August 18, 2019

Published: August 21, 2019

Copyright $\odot 2019$ by author(s) and Scientific Research Publishing Inc. This work is licensed under the Creative Commons Attribution International License (CC BY 4.0).

http://creativecommons.org/licenses/by/4.0/

(c) (i) Open Access

\begin{abstract}
In this paper, a valuation framework is developed for the variable rate demand obligation (VRDO). The VRDO is a class of floating rate note whose coupon rate changes on a regular basis and is "puttable" by the bondholder, given a notice of one week to the issuer. We model the coupon rate as a geometric Brownian motion process and assume that the incidence of puts is Poisson distributed, across time. Put events are assumed to be brought about by factors such as a change in the liquidity and consumption preferences of investors or a change in a Municipal issuer's creditworthiness. This paper is unique because as of July 2019 there exists no attempt at valuing VRDOs in the research literature.
\end{abstract}

\section{Keywords}

Variable Rate Demand Obligation, Municipal Corporation, Public Policy, Stochastic Calculus

\section{Introduction}

The purpose of this paper is to develop a valuation framework for a variable rate demand obligation (VRDO). There exists no valuation formula in the literature and so an attempt is made to construct a parsimonious framework of valuation for the VRDO. VRDOs exist predominantly in the United States than in other countries. The concepts underlying the VRDO are simple. They are floating rate obligations that have a nominal long-term maturity but have a coupon rate that is reset either daily or less frequently, depending upon the terms and conditions specified in the bond agreement (Dawson [1] [1993]). Investors accrue interest on a continuous basis and may put the bond back with the issuer at any time. When the bondholder exercises the put option they receive the par value of the 
bond with accrued interest. The major issuers of VRDOs in the US have been electric utilities, colleges and universities and some large water companies. An 1895 court decision, Pollock versus Farmer's Loan and Trust Co., established Municipal securities' interest income as tax-free (Walter [2] [1986]).

The unusually short-term interval over which the coupon rate is adjusted means that the valuation of this instrument can be valued within a continuous-time finance context. In this paper, a stochastic model is developed in which the coupon rate follows a geometric Brownian motion process and the arrival time of the put by the investor conforms to negative exponential distribution. The latter is equivalent to the probability of an arrival, within a given time interval, being Poisson distributed.

The advantages of using VRDOs are that they have led to a lowering of the cost of capital by many municipal issuers. Indeed, VRDOs were introduced at the beginning of the 1980s when long-term interest rates were considerably higher than short-term rates. VRDOs provide flexibility for issuers to restructure their debt because advance refunding restrictions do not apply to VRDOs as they apply to fixed-rate debt. However, the issue is rated by Standard and Poors in terms of their financial liquidity and credit-worthiness. A change in the bond rating of a municipal or corporate issuer could cause bondholders to put the VRDO back with the issuer if they suspected possible future financial distress.

The disadvantages of VRDOs from the perspective of the issuer are that in a period of rising interest rates, they will find themselves paying a higher coupon, possibly until maturity. If the bonds are put by the investor when interest rates are high, the issuer faces higher borrowing costs to reissue, as well as transaction costs. In addition, certain market conditions may cause many investors to put back their bonds with the issuer simultaneously.

\subsection{Classes of VRD0s}

The most common form of VRDO is the "lower floater", in which the interest rate is adjusted weekly with respect to a specified index. With lower floaters, bond holders must give the issuer seven days notice if they wish to put the bonds ([Moody's Investors Service Inc. [3] [1987]). Longer-term VRDOs allow the coupon rate to be reset monthly or quarterly. Some floaters can be put at any time by the investor, whereas others can only be put on the interest adjustment date [4] [Epstein, 1992].

\subsection{Interest Rates}

The coupon rate for VRDOs is assigned according to a rate on a specified interest rate index that reflects the current short-term rate (Moody's Investors Service [1987]) [3]. Hence, a potential long-term liability is financed at short-term rates.

\subsection{Rating Procedures}

Bond rating agencies decompose the risk of VRDOs into two components. The first is a creditworthiness rating which reflects the issuer's ability to pay the 
coupon over the life of the bond. The second, the liquidity rating represents the ability of the issuer to make timely payments, if the bond is put by the investors. The latter, depends upon the terms in the credit agreement between the issuer and the commercial bank (Standard and Poors Corporation [5] [1994]).

The credit factors that Standard and Poors focus upon when determining the impact of floating rate debt are the issuer's debt management strategy; floating rate and short-term exposure as a percentage of total debt; financial flexibility and liquidity resources; and synthetic floating rate risks, such as termination payment risk and counterparty risk. The advantage of issuing floating rate debt is that it helps issuers match assets and liabilities. Increased debt service costs associated with a rise in interest rates are offset by increases in investment income and vice-versa.

\subsection{Remarketing of VRDOs after Puts}

The structure of long-term variable rate demand obligations involves the issuer engaging in an agreement with a commercial bank to remarket the debt to possible other investors should the bondholder exercise their put option. The remarketing agent resets the coupon rate and attempts to resell the bonds. If after this process some bonds remain unsold, the issuer's remaining cash flows are satisfied by the credit facility provided by the commercial bank [Dawson [1], 1983]. The credit agreement between the bond issuer and commercial agreement will normally specify that either the bank will underwrite the reissue or provide the issuer with a loan to match any short fall in the issuer's cash flows arising from the exercise of the put option by the bond holder (Standard and Poors Corporation [6] [1990]). If the bank chooses to make a loan rather than to purchase the excess bonds, then the interest rate charged will be connected to the bank prime rate (Peterson [7] [1991]).

Factors which cause bondholders to 'put' the VRDO back with the issuer may be wide-ranging. These could be a change in credit rating by Standard and Poors, a change in the liquidity or consumption preferences of the bondholder or personal taxation implications.

Finally, there has been some recent litigation in the US relating to VRDO by Baltimore against ten banks for violating antitrust and state law, alleging collusion in market manipulation of VRDOs (Bloomberg Law [8], 2019).

\section{Valuing the Variable Rate Demand Obligation}

Consider a domestic bond subject to a variable coupon rate $i$. The coupon payment during $\mathrm{d} t$ is $P i \mathrm{~d} t$. When the bondholder puts the bond, the value of the bond is $P(1+h)$, which includes the premium at the proportionate rate $h$ (normally $h=0$ because the bonds are usually repaid at par). Now, the time to the put being exercised, after any initial period within which putting is not allowed is assumed to be negatively exponentially distributed, with mean $1 / \lambda$. This is consistent with a Poisson arrival rate of $\lambda$. Hence, the probability of a put during 
$\mathrm{d} t$ is $\lambda \mathrm{d} t$. However, given a market value of $m$, and a put during $\mathrm{d} t$ being possible, then if the bond is not put, the expected value at the end of the period will be $E(m+\mathrm{d} m)$, with an associated probability of $(1-\lambda \mathrm{d} t)$. By discounting at the rate $k$ during $\mathrm{d} t$, it follows that the value of the bond is:

$$
m=P i \mathrm{~d} t+P(1+h) \lambda \mathrm{d} t /(1+k \mathrm{~d} t)+E(m+\mathrm{d} m)(1-\lambda \mathrm{d} t) /(1+k \mathrm{~d} t)
$$

This accounts for the coupon flows and the end of period value with or without the bond being put.

Now, let the coupon rate follow a geometric Brownian motion with a growth trend parameter of $\mu$ and a standard deviation parameter of $\sigma$.

$$
i=\mu i \mathrm{~d} t+\sigma i \mathrm{~d} z
$$

where,

$$
\mathrm{d} z=n(\mathrm{~d} t)^{1 / 2}
$$

i.e. $n$ is a standard normally distributed variable. From Itô's [1965] lemma [9]:

$$
E(\mathrm{~d} m)=\frac{\mathrm{d} m}{\mathrm{~d} i} \mu i \mathrm{~d} t+\frac{1}{2} \frac{\mathrm{d}^{2} m}{\mathrm{~d} i^{2}} \sigma^{2} i^{2} \mathrm{~d} t .
$$

Now,

$$
\lambda \mathrm{d} t /(1+k \mathrm{~d} t)=\lambda \mathrm{d} t(1-k \mathrm{~d} t) /\left(1-k^{2}(\mathrm{~d} t)^{2}\right)=\lambda \mathrm{d} t
$$

ignoring terms in $(\mathrm{d} t)^{2}$. Also,

$$
(1-\lambda \mathrm{d} t) /(1+k \mathrm{~d} t)=(1-\lambda \mathrm{d} t)(1-k \mathrm{~d} t) /\left(1-k^{2}(\mathrm{~d} t)^{2}\right)=1-\lambda \mathrm{d} t-k \mathrm{~d} t
$$

again ignoring terms in $(\mathrm{d} t)^{2}$. Therefore,

$$
m=P i \mathrm{~d} t+P(1+h) \lambda \mathrm{d} t+\left(m+\frac{\mathrm{d} m}{\mathrm{~d} i} \mu i \mathrm{~d} t+\frac{1}{2} \frac{\mathrm{d}^{2} m}{\mathrm{~d} i^{2}} \sigma^{2} i^{2} \mathrm{~d} t\right)(1-\lambda \mathrm{d} t-k \mathrm{~d} t) .
$$

Hence, ignoring terms in $(\mathrm{d} t)^{2}$ :

$$
\frac{1}{2} \frac{\mathrm{d}^{2} m}{\mathrm{~d} i^{2}} \sigma^{2} i^{2}+\frac{\mathrm{d} m}{\mathrm{~d} i} \mu i-(\lambda+k) m=P(i+(1+h) \lambda) .
$$

Since this a second-order linear non-homogeneous differential equation, the solution is given by the sum of the general solution to the corresponding homogeneous version of the equation plus any particular solution to the non-homogeneous equation. Dixit and Pindyck [10] [1994] have demonstrated that by ignoring the possibilities of non-economic solutions and speculation, the general solution to the homogeneous version of an equation of this type is zero. Now the right-hand side of the Equation (8) is a linear function in $i$. Hence, we can introduce a linear trial function in order to determine any particular solution. Therefore, let

$$
m=a i+b \text {, where } a \text { and } b \text { are constants. }
$$

Since $\mathrm{d} m / \mathrm{d} i=a$ and $\mathrm{d}^{2} m / \mathrm{d} I^{2}=0$, we can make substitutions accordingly in Equation (8):

$$
0+a \mu i-(\lambda+k)(a i+b)=-P(i+(1+h) \lambda)
$$

Equating the coefficients of $i$ gives: 


$$
a=P /(k-\mu+\lambda)
$$

And similarly for constant terms:

$$
b=P(1+h) \lambda /(k+\lambda) .
$$

By substituting these values into Equation (9):

$$
m=P\{i /(k-\mu+\lambda)+\lambda(1+h) /(k+\lambda)\} .
$$

This represents the value of the bond, when the put is exercised at any time.

Now, if there are restrictions, preventing the bond being put during the first $y$ years, then the present value, $I$ of the coupon flows during this period will be:

$$
I=\int_{0}^{y} P i \mathrm{e}^{\mu t} \mathrm{e}^{-k t} \mathrm{~d} t=P i\left(1-\mathrm{e}^{-(k-\mu) y}\right) /(k-\mu) .
$$

In Equation (14) we can interpret $i$ as the initial variable coupon rate. Also, in Equation (13), we can replace $i$ by $i \mathrm{e}^{\mu y}$ to reflect the expected coupon rate in $y$ years' time and then discount the whole expression at the rate $k$. Therefore, the initial value of the bond, $m_{0}$, is:

$$
m_{0}=P i\left(1-\mathrm{e}^{-(k-\mu) y}\right) /(k-\mu)+P \mathrm{e}^{-k y}\left[i \mathrm{e}^{\mu y} /(k-\mu+\lambda)+\lambda(1+h) /(k+\lambda)\right]
$$

The discrete equivalent is:

$$
m_{0}=\frac{P i}{k-\mu}\left\{1-\left(\frac{1+\mu}{1+k}\right)^{y}\right\}+\frac{P}{(1+k)^{y}}\left[\frac{i(1+\mu)^{y}}{k-\mu+\lambda}+\frac{\lambda(1+h)}{k+\lambda}\right] .
$$

\section{Example}

Suppose $\$ 100$ nominal debt is priced at $\$ 106.94$. The variable coupon rate is 7 per cent with an expected trend of 0.5 per cent per annum. After 5 years the debt can be put. The Poisson event is expected to occur a further 4 years later. The premium on redemption is 3 percent.

Thus for $P=100, m_{0}=106.94, i=0.07, \mu=0.005, y=5,1 / \lambda=4$ and $h=0.03$, the cost of funds is 6 per cent, which satisfies Equation (16).

\section{Summary}

This paper has valued the variable rate demand obligation, an important security issued by municipal corporations in the US. The framework assumed that the coupon rate followed a geometric Brownian motion process and that put by investors were Poisson distributed across time. The framework gives rise to a valuation equation that is closed form. Further research may help to refine our model and incorporate the impact of taxation because increasingly, VRDOs are being issued by municipal corporations. This paper is unique because as of July 2019 there exists no attempt at valuing VRDOs in the research literature.

\section{Conflicts of Interest}

The authors declare no conflicts of interest regarding the publication of this paper. 


\section{References}

[1] Dawson, W. (1993) Variable Rate Demand Notes. In: Lamb, R., Leighland, J. and Rappaport, S., Eds., The Handbook of Municipal Bonds and Public Finance, New York Institute of Finance, New York, 531-535.

[2] Walter, J. (1986) Short-Term Municipal Securities. Economic Review Federal Reserve Bank of Richmond, 72, 25-34.

[3] Moody's Investors Service (1987) Moody's on Municipals: An Introduction to Issuing Debt. New York, 19-20.

[4] Epstein, L. (1992) Basis Points: Put up with Floaters; Put up with the Phones. Corporate Cash Flow, 13, 46-47.

[5] Standard and Poors Corporation (1994) Municipal Finance Criteria. New York, 5.

[6] Standard and Poors Corporation (1994) Municipal Finance Criteria. New York, 92.

[7] Peterson, J.E. (1991) Debt Markets and Instruments. In: Peterson, J.E. and Strachota, D.R., Eds., Local Government Finance: Concepts and Practices, Government Finance Officers Association, Chicago, 308.

[8] Bloomberg Law (2019) Baltimore Sues 10 Banks over VRDOs, Alleging Price Collusion. Securities Law News.

https://news.bloomberglaw.com/securities-law/baltimore-sues-10-banks-over-vrdos -alleging-price-collusion-2

[9] Itô, K. (1965) On Stochastic Differential Equations. Memoirs of the American Mathematical Society, 4, 1-51.

[10] Dixit, A.K. and Pindyck, R.S. (1994) Investment under Uncertainty. Princeton University Press, Princeton. 